IJIS Indonesian Journal on Information System

\title{
SISTEM INFORMASI AKADEMIK BERBASIS WEB PADA POLITEKNIK SAINS DAN TEKNOLOGI WIRATAMA MALUKU UTARA
}

\author{
ACADEMIC WEB-BASED INFORMATION SYSTEM IN POLITEKNIK \\ SCIENCE AND TECHNOLOGY WIRATAMA NORTH MALUKU
}

\author{
Faisal Kamran ${ }^{1}$, N Faisal Kharie ${ }^{2}$ \\ Program Studi Teknik Komputer, \\ Politeknik Sains dan Teknologi Wiratama Maluku Utara \\ faisal.kamran@gmail.com
}

\begin{abstract}
Abstrak
Politeknik Sains dan Teknologi Wiratama Maluku Utara merupakan salah satu perguruan tinggi swasta pada bidang Teknologi Informasi yang ada pada kota ternate. Sebagai perguruan tinggi yang keberadaannya tidak lepas dari proses komunikasi secara luas baik kepada mahasiswa maupun kepada masyarakat luas. Saat ini, sistem pengelolaan informasi di Politeknik Sains dan Teknologi Wiratama Maluku Utara masih bersifat konvensional, dimana dalam penyampaian informasi seperti profil kampus, data mahasiswa, data dosen, informasi penerimaan mahasiswa baru. dalam pengelolaan dan penyampaian informasi masih mengandalkan brosur atau memuat pada media surat kabar atau majalah. Dalam penyelenggaran Informasi yang mengandalkan media tersebut membutuhkan sosialisasi dan biaya yang sangat besar sehingga dianggap kurang efektif dalam penyampaian informasi tersebut, Sistem yang dirancang menggunakan bahasa pemrograman PHP, HTML, CSS dan database MySQL. Diharapkan dapat memberikan kemudahan pada pihak kampus dalam menyelenggarakan informasi serta kegiatan kampus dan menunjang kinerja administrasi dalam mengelola informasi tersebut agar masyarakat atau mahasiwa yang ingin mengetahui informasi dan kegiatan kampus dapat melihat pada sistem tersebut
\end{abstract}

Kata Kunci : Sistem Informasi, Akademik, Website

\begin{abstract}
Polytechnic Science and technology Wiratama North Maluku is one of the private universities in the field of information technology in the ternate city. As a college whose existence cannot be separated from the process of communication extensively both to students and to the community at large. Currently, the system of information management in Polytechnic University of science and technology North Maluku Wiratama still conventional in nature, wherein the submission of information such as profile campus, student data, data of Lecturer, admissions information. in the management and delivery of information still, rely on brochures or contains media of newspapers or magazines. Before relying on in conducting these media require socialization and the enormous costs that are considered less effective in the delivery of such information, the System is designed using the programming language PHP, HTML, CSS, and MySql database. Expected to provide the convenience of on-campus parties in organizing campus activities and information and support the performance of the Administration in managing such information in order for the community or students who want to find out information and the activities of the campus can be viewed on the system
\end{abstract}

Keyword: Information System, Academic, Website 


\section{PENDAHULUAN}

Kemajuan teknologi informasi dan komunikasi saat ini banyak memberikan kemudahan bagi aktivitas manusia disegala bidang. Pengelolaan data-data untuk menjadi informasi yang sebelumnya rumit dan membutuhkan waktu lama dalam penyelesaiannya, menjadi cepat dan ringan bila dikerjakan menggunakan fasilitas teknologi. Akibatnya, kebutuhan manusia akan teknologi semakin tinggi karena dapat membantu efektivitas dan efisiensi suatu pekerjaan.

Kebutuhan yang mendasar dalam pengelolaan informasi sangat dirasakan pada semua organisasi mana pun baik itu instansi pemerintahan, lembaga swasta dan terlebih lagi perguruan tinggi. Hal ini sejalan dengan apa yang telah dinyatakan oleh Taufiq (2013:15) yang menyimpulkan bahwa Informasi adalah data-data yang diolah sehingga memiliki nilai tambah dan bermanfaat bagi pengguna. Melihat begitu besar nilai informasi (value of information), sehingga kecanggihan teknologi berupa komputer dan internet senantiasa dikembangkan guna mempermudah akses informasi bagi masyarat

Politeknik Sains dan Teknologi Wiratama Maluku Utara merupakan salah satu perguruan tinggi swasta yang ada pada kota ternate. Sebagai perguruan tinggi yang keberadaannya tidak lepas dari proses komunikasi secara luas baik kepada mahasiswa maupun kepada masyarakat luas. Saat ini, sistem pengelolaan informasi di Politeknik Sains dan Teknologi Wiratama Maluku Utara masih bersifat konvensional, dimana dalam penyampaian informasi seperti profil kampus, data mahasiswa, data dosen, informasi penerimaan mahasiswa baru. dalam pengelolaan dan penyampaian informasi masih mengandalkan brosur atau memuat pada media surat kabar atau majalah. Dalam penyelenggaran Informasi yang mengandalkan media tersebut membutuhkan sosialisasi dan biaya yang sangat besar sehingga dianggap kurang efektif dalam penyampaian informasi tersebut

Dengan melihat masalah yang di hadapi oleh Politeknik Sains dan Teknologi Wiratama Maluku Utara, maka peneliti merancang Sistem Informasi Akademik Berbasis Web pada Politeknik Sain dan Teknologi Wiratama Maluku Utara

Sistem yang dirancang menggunakan bahasa pemrograman PHP, HTML, CSS dan database MySql. Diharapkan dapat memberikan kemudahan pada pihak kampus dalam menyelenggarakan informasi serta kegiatan kampus dan menunjang kinerja administrasi dalam mengelola informasi tersebut agar masyarakat atau mahasiwa yang ingin mengetahui informasi dan kegiatan kampus dapat melihat pada sistem tersebut

\section{Rumusan Masalah}

Masalah dalam penilitian ini adalah Bagaimana merancang Sistem Informasi Akademik Berbasis Web pada Politeknik Sains dan Teknologi Wiratama Maluku Utara Untuk memberikan kemudahan pada pihak kampus dalam menyelenggarakan informasi serta kegiatan kampus dan menunjang kinerja administrasi dalam mengelola informasi tersebut agar masyarakat atau mahasiwa yang ingin mengetahui informasi dan kegiatan kampus dapat melihat pada sistem tersebut

\section{LANDASAN TEORI Pengertian Sistem}

Taufiq (2013:2) menyimpulkan bahwa Sistem adalah kumpulan dari sub-sub 
sistem baik abstrak maupun fisik yang saling terintegrasi dan berkolaborasi untuk mencapai suatu tujuan tertentu

ciri-ciri sistem di bagi tujuh bagian yaitu :

1. Tujuan sistem

Tujuan merupakan sasaran atau hasil yang diinginkan. Sedangkan sistem yang baik adalah sistem yang memiliki tujuan yang jelas dan terukur yang memungkinkan untuk dicapai dan memiliki langkah-langkah yang terstruktur untuk mencapainya.

2. Batas sistem

Batas sistem perupakan hal penting harus ditetntukan dari awal karena dengan batas yang jelas maka sistem yang lebih muda untuk didefenisikan dan dimengerti. Sampai saat ini tidak ada kesepakatan batas untuk sebuah sistem karena dengan sistem yang sama memungkinkan mempunyai batas yang berbeda tergantung kebutuhan dari sistem itu sendiri.

3. Subsistem

Secara sederhana subsistem merupakan komponen-komponen atau sistem-sistem yang lebih kecil yang ada didalam sistem itu sendiri. Penentuan sub sistem merupakan hal yang penting untuk memberi batasan antara lingkungan dalam dengan lingkungan luar. Dengan menentukan sub-sub sistem dengan baik atau tepat maka sistem itu akan lebih mudah untuk dipahami dan diklasifikasikan.

4. Input

Input merupakan semua kegiatan (pencatatan, pengetikan, pengeditan) atau memasukkan data baik fisik ataupun non fisik/logic. Input fisik merupakan berkas-berkas, data-data laporan, benda-benda dan lain-lain. Sedangkan input logic bisa berupa data dari flashdisk, disket, $\mathrm{CD}$ dan tempat penyimpanan lainnya.

5. Proses

Proses adalah suatu kegiatan yang merubah input sehingga menjadi output yang memiliki nilai tambah atau berguna lagi. Dalam hal ini input dan output yang dimaksud adalah data menjadi informasi.Proses (pemrosesan) sangatlah penting untuk diperhatikan karena dengan proses yang tidak terstruktur maka hasilnya juga susah untuk menjadi maksimal tapi jika langkah-langkah yang dilakukan dalam proses sangat terstruktur, efektif, dan efisien maka sesuatu yang dihasilkan akan lebih sempurna atau berkualitas, maka dari itu dalam melakukan proses usahakan bisa seefektif dan seefisien mungkin.

6. Output

Output merupakan hasil dari input yang diproses, output sering disebut sebagai informasi. Yang membedakan output dengan input adalah kalau output nilainya sudah tambah dan lebih bermanfaat bagi pengguna.

7. Feedback

Feedback atau umpan balik atau memberi makna kembali merupakan sebuah kegiatan yang memasukkan output kembali dalam input. Dalam hal ini output disebut sebagai informasi dan input adalah data. Bila output dinilai kurang maksimal dan dilakukan evaluasi lagi terhadap input dan proses, itulah yang disebut dengan Feedback. Selain itu informasi yang sudah didapat bisa dijadikan sebagai input lagi menjadikan informasi sebagai data yang akan diolah lagi hal seperti itu juga bisa disebut sebagai feedback.

\section{Pengertian Informasi}


Kusrini (2007) dalam Taufiq (2013:15) mendefinisakan bahwa informasi merupakan hasil olahan data, dimana data tersebut sudah diproses dan diinterpretasikan menjadi sesuatu yang bermakna untuk pengambilan keputusan. Informasi juga diartikan sebagai himpunan dari data yang relevan dengan satu atau beberapa orang dalam suatu waktu

\section{Pengertian Sistem Informasi}

Taufiq (2013:17) mendefinisikan Sistem Informasi adalah kumpulan dari sub-sub sistem yang saling terintegrasi dan berkolaborasi untuk menyelesaikan masalah tertentu dengan cara mengolah data dengan alat yang namanya komputer sehingga memiliki nilai tambah dan bermanfaat bagi pengguna.

\section{Konsep Web (Website)}

Menurut Nuruddin (2013) WWW (World Wide Web) atau juga dikenal dengan WEB adalah salah satu layanan yang didapat oleh pemakai komputer yang terhubung ke internet. Web ini menyediakan informasi bagi pemakai komputer yang terhubung ke internet dari sekedar informasi "sampah" atau informasi yang tidak berguna sama sekali sampai informasi yang serius; dari informasi yang gratisan sampai informasi yang komersial. Website atau situs dapat diartikan sebagai kumpulan halamanhalaman yang digunakan untuk menampilkan informasi teks, gambar diam atau gerak, animasi, suara, dan atau gabungan dari semuanya itu baik yang bersifat statis maupun dinamis yang membentuk satu rangkaian bangunan yang saling terkait dimana masing-masing dihubungkan satu sama lain

\section{Sistem Informasi Akademik}

Akademik adalah suatu bidang yang mempelajari tentang kurikulum atau pembelajaran dalam fungsinya untuk meningkatkan pengetahuan dalam segi pendidikan / pembelajaran yang dapat dikelola oleh suatu sekolah atau lembaga pendidikan (Catur, 2009).

Sistem Informasi Akademik adalah perangkat lunak yang digunakan untuk menyajikan informasi dan menata administrasi yang berhubungan dengan kegiatan akademik. Dengan penggunaan perangkat lunak seperti ini diharapkan kegiatan administrasi akademik dapat dikelola dengan baik dan informasi yang diperlukan dapat diperoleh dengan mudah dan cepat (Satoto, 2008).

\section{Konsep HTML, PHP, MySQL dan CSS}

\section{HTML}

Sunarfrihantono (2002:1) HTML (Hypertext Markup Language) merupakan salah satu format yang digunakan dalam pembuatan dokumen dan aplikasi yang berjalan dihalaman web. Oleh karena itu agar dapat membuat program aplikasi diatas halaman web, terlebih dahulu harus mengenal dan menguasai HTML. Protokol yang digunakan untuk mentransfer data antara web server ke web browser ialah HTTP (Hypertext Transfer Protocol). Protokol ini mentransfer dokumendokumen web yang ditulis atau berformat HTML (Hypertext Markup Language).

\section{PHP}

Saputra (2011:1) PHP atau yang memiliki kepanjangan PHP Hypertext Preprocessor merupakan suatu bahasa pemrograman yang difungsikan untuk membangun suatu website dinamis. PHP menyatu dengan kode HTML, maksudnya adalah beda kondisi. HTML digunakan sebagai pembangun atau pondasi dari kerangka layout web, sedangkan PHP 
difungsikan sebagai prosesnya sehingga dengan adanya PHP tersebut, sebuah web akan sangat mudah dimaintenance. PHP berjalan pada sisi server sehingga PHP disebut juga sebagai bahasa Server Side Scripting. Artinya bahwa dalam setiap/untuk menjalankan PHP wajib adanya seb server.

\section{MySQL}

Saputra (2011 : 69) secara umum, database berfungsi sebagai tempat atau wadah untuk menyimpan, mengklasifikasikan data secara profesional.

MySQL bekerja menggunakan SQL Language (Structure Query Language). Itu dapat di artikan bahwa MySQL merupakan stadar penggunaan database di dunia untuk pengolaan data

\section{CSS}

Kurniawan (2008:1) dalam buku yang berjudul desain web praktis dengan CSS menjelaskan bahwa CSS atau Cascading Style Sheets adalah sebuah dokumen yang berisi aturan yang digunakan untuk memisahkan isi dengan layout dalam halaman-halaman web yang dibuat. CSS memperkenalkan "template" yang berupa style untuk dibuat dalam mengizinkan penulisan kode yang lebih mudah dari halaman-halaman web yang dirancang.

\section{Pengertian DFD (Data Flow Diagram)}

Data flow diagram atau yang disingkat DFD merupakan suatu diagram yang menggambarkan alir data dalam suatu entitas ke sistem atau sistem ke entitas (Saputra, 46:2013). DFD juga dapat diartikan sebagai teknis grafis yang menggambarkan alir data dan transformasi yang digunakan sebagai perjalanan data dari input atau masukkan menuju keluaran atau output

\section{Alur Penelitian}

Pada alur penelitian merupakan tahaptahap perencanaan yang akan dilakukan dalam penilitian pengembangan sistem, berikut merupakan tampilan gambar alur penilitian sebagai berikut:

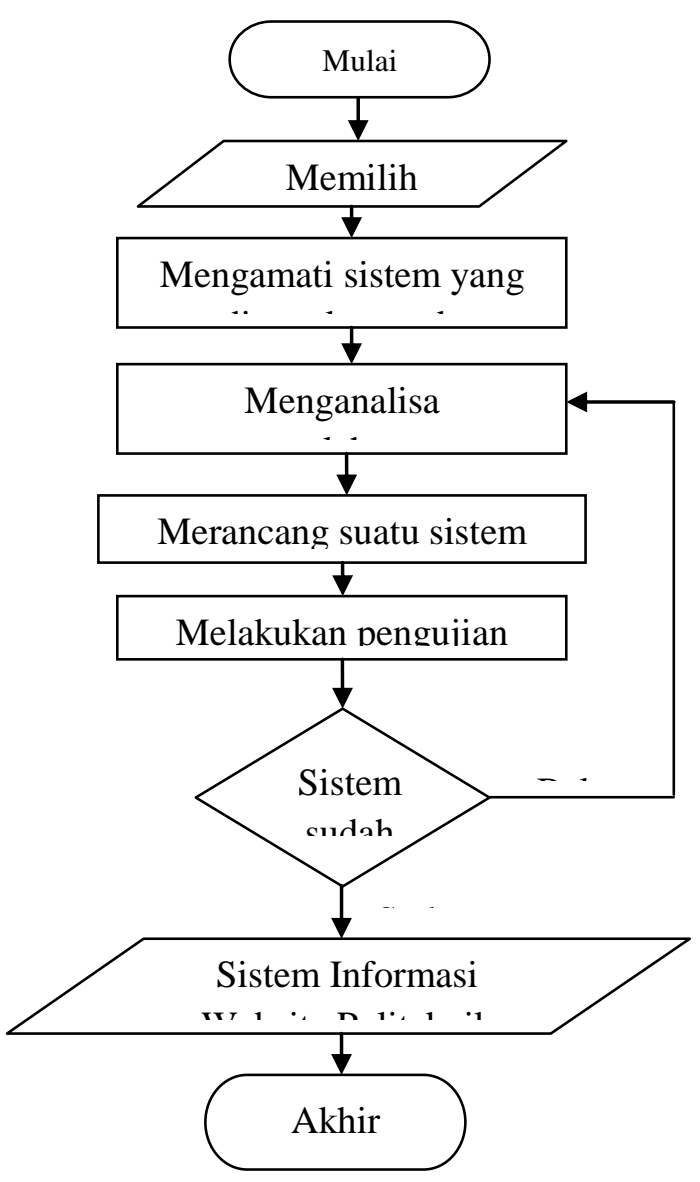

Gambar 1 : Alur Penelitian

\section{METODE PENELITIAN}

Metodologi penelitian yang digunakan pe nelitian ini adalah :

1. Observasi.

Observasi yaitu peneliti melakukan pengamatan secara langsung terhadap sistem informasi yang sementara diterapkan pada objek penelitian.

2. Wawancara.

Wawancara (Interview) adalah proses memperoleh keterangan untuk tujuan 
penelitian dengan cara tanya jawab, sambil bertatap muka antara si penanya atau pewancara dengan si penjawab atau resonden dengan menggunakan alat yang dinamakan interview guide (panduan wawancara) (Nazir: 2003: 193) dalam Asnawi dan Masyhuri (2009:163). Untuk itu Peneliti akan mewawancarai secara langsung kepada staff biro Politeknik Sains dan Teknologi Wiratama Maluku Utara untuk mendapatkan informasi terkait dengan kebutuhan penelitian.

\section{Analisa sistem yang berjalan}

Berikut adalah alur sistem yang berjalan di tampilkan pada pada Flowchart system dapat dilihat pada gambar berikut

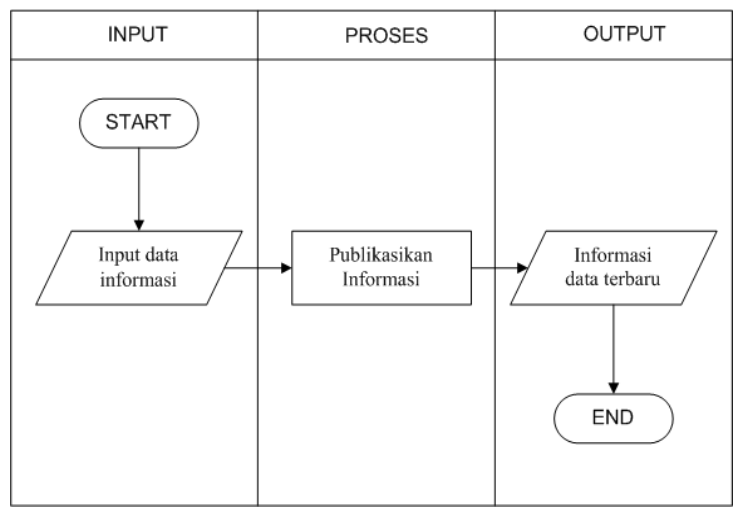

Gambar 2 : Flowchart Sistem Yang Berjalan

\section{Rancangan system yang di usulkan}

Rancangan Sistem yang di usulkan merupakan sistem yang baru dapat di tampilkan pada gambar flowchart Sebagai berikut:

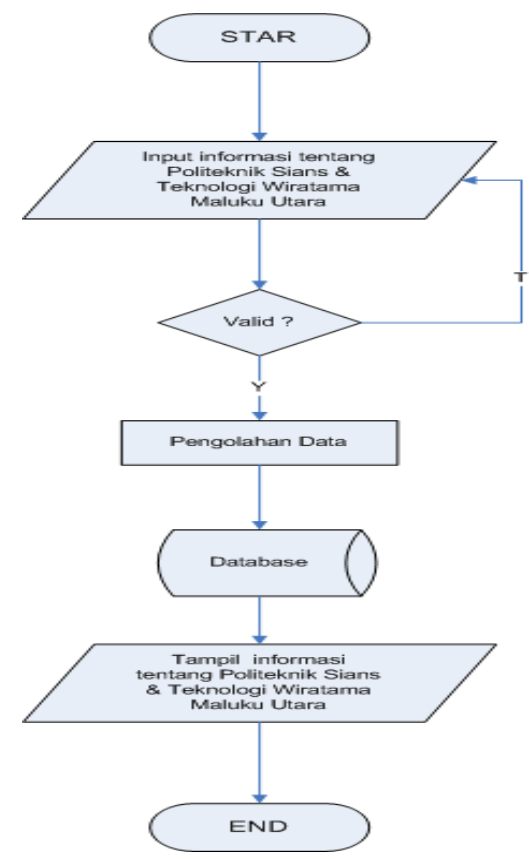

Gambar 3 : Flowchart Sistem Yang diusulkan

\section{Alat dan bahan penelitian}

Untuk merancang game maka peneliti memakai alat- alat di bawah ini

\section{Software}

1. Sistem opersai windows 7 ultimate

2. Notepad++ 6.5.4

3. Web server XAMPP 1.8.3 (Apache, MySQL)

4. Bahasa pemrograman HTML, PHP, SQL dan CSS

\section{Hardware}

1. Processor intel Core i3 2328M (2.2GHz, 3MB L3 cache)

2. Intel HD Graphics 3000

3. LCD LED HD 14.0"

4. Mainboard Intel.

5. RAM 2 GB DDR3.

6. Hardisk $500 \mathrm{~GB}$.

\section{Tabel Admin}


Tabel admin digunakan untuk menyimpan data admin. Spesifikasi dari tabel admin sebagai berikut :

Tabel 1 : Tabel Admin

\begin{tabular}{|c|c|c|c|}
\hline Field & Type & Lenght & PrimaryKey \\
\hline Username & Varchar & 30 & $*$ \\
\hline password & Varchar & 30 & \\
\hline
\end{tabular}

\section{Tabel berita}

Tabel berita digunakan untuk menyimpan berita kegiatan kampus baik oleh mahasiswa maupun dosen. Spesifikasi tabelnya sebagai berikut

Tabel 2 : Tabel Admin

\begin{tabular}{|l|c|c|c|c|}
\hline \multicolumn{1}{|c|}{ Field } & Type & $\begin{array}{c}\text { Len } \\
\text { ght }\end{array}$ & $\begin{array}{c}\text { Primary } \\
\text { Key }\end{array}$ & $\begin{array}{c}\text { Autoincre } \\
\text { ment }\end{array}$ \\
\hline $\begin{array}{l}\text { id_berit } \\
\text { a }\end{array}$ & Int & 11 & $*$ & $*$ \\
\hline $\begin{array}{l}\text { tgl_post } \\
\text { ing }\end{array}$ & $\begin{array}{c}\text { Varch } \\
\text { ar }\end{array}$ & 30 & & \\
\hline $\begin{array}{l}\text { jam_pos } \\
\text { ting }\end{array}$ & $\begin{array}{c}\text { Varch } \\
\text { ar }\end{array}$ & 10 & & \\
\hline $\begin{array}{l}\text { judul_b } \\
\text { erita }\end{array}$ & $\begin{array}{c}\text { Varch } \\
\text { ar }\end{array}$ & 50 & & \\
\hline Gambar & $\begin{array}{c}\text { Varch } \\
\text { ar }\end{array}$ & 50 & & \\
\hline $\begin{array}{l}\text { isi_berit } \\
\text { a }\end{array}$ & $\begin{array}{c}\text { Longt } \\
\text { ext }\end{array}$ & & & \\
\hline $\begin{array}{l}\text { user_po } \\
\text { st }\end{array}$ & $\begin{array}{c}\text { Varch } \\
\text { ar }\end{array}$ & 30 & & \\
\hline
\end{tabular}

\section{Tabel Dosen}

Tabel dosen digunakan untuk menyimpan informasi tentang tenaga dosen atau tenaga pengajar. Spesifikasi tabelnya sebagai berikut :

Tabel 3 : Tabel Dosen

\begin{tabular}{|l|c|c|c|c|}
\hline Field & Type & $\begin{array}{c}\text { Leng } \\
\text { ht }\end{array}$ & $\begin{array}{c}\text { Primary } \\
\text { Key }\end{array}$ & $\begin{array}{c}\text { Autoincre } \\
\text { ment }\end{array}$ \\
\hline $\begin{array}{l}\text { id_dos } \\
\text { en }\end{array}$ & Int & 11 & $*$ & $*$ \\
\hline $\begin{array}{l}\text { nma_d } \\
\text { sn }\end{array}$ & $\begin{array}{c}\text { Varch } \\
\text { ar }\end{array}$ & 50 & & \\
\hline $\begin{array}{l}\text { lulusa } \\
\text { n }\end{array}$ & $\begin{array}{c}\text { Varch } \\
\text { ar }\end{array}$ & 50 & & \\
\hline
\end{tabular}

\section{Tabel Prodi}

Tabel pertanyaan digunakan untuk menyimpan data pertanyaan yang dikirimkan oleh pengunjung dari form hubungi kami. Spesifikasi tabelnya sebagai berikut :

Tabel 4 : Tabel Prodi

\begin{tabular}{|l|c|c|c|c|}
\hline \multicolumn{1}{|c|}{ Field } & $\begin{array}{c}\text { Typ } \\
\text { e }\end{array}$ & $\begin{array}{c}\text { Len } \\
\text { ght }\end{array}$ & $\begin{array}{c}\text { Primar } \\
\text { yKey }\end{array}$ & $\begin{array}{c}\text { Autoincr } \\
\text { ement }\end{array}$ \\
\hline id_prodi & Int & 11 & $*$ & $*$ \\
\hline $\begin{array}{l}\text { program_pe } \\
\text { ndidikan }\end{array}$ & $\begin{array}{c}\text { Varc } \\
\text { har }\end{array}$ & 30 & & \\
\hline informasi & Text & & & \\
\hline tgl_post & date & & & \\
\hline user_post & $\begin{array}{c}\text { Varc } \\
\text { har }\end{array}$ & 30 & & \\
\hline
\end{tabular}

\section{Tabel Profil}

Tabel pertanyaan digunakan untuk menyimpan data pertanyaan yang dikirimkan oleh pengunjung dari form hubungi kami. Spesifikasi tabelnya sebagai berikut :

Tabel 5 : Tabel Profil

\begin{tabular}{|l|c|c|c|c|}
\hline \multicolumn{1}{|c|}{ Field } & Type & $\begin{array}{c}\text { Leng } \\
\text { ht }\end{array}$ & $\begin{array}{c}\text { Primary } \\
\text { Key }\end{array}$ & $\begin{array}{c}\text { Autoincre } \\
\text { ment }\end{array}$ \\
\hline $\begin{array}{l}\text { id_pro } \\
\text { fil }\end{array}$ & Int & 11 & $*$ & $*$ \\
\hline profil & $\begin{array}{c}\text { Varc } \\
\text { har }\end{array}$ & 30 & & \\
\hline $\begin{array}{l}\text { inform } \\
\text { asi }\end{array}$ & Text & & & \\
\hline $\begin{array}{l}\text { tgl_po } \\
\text { st }\end{array}$ & $\begin{array}{c}\text { Varc } \\
\text { har }\end{array}$ & 30 & & \\
\hline $\begin{array}{l}\text { user_p } \\
\text { ost }\end{array}$ & $\begin{array}{l}\text { Varc } \\
\text { har }\end{array}$ & 30 & & \\
\hline
\end{tabular}

\section{Tabel Testimoni Alumni}

Tabel pertanyaan digunakan untuk menyimpan data pertanyaan yang dikirimkan oleh pengunjung dari form hubungi kami. Spesifikasi tabelnya sebagai berikut :

Tabel 6 : Tabel Testimoni Alumni

\begin{tabular}{|l|c|c|c|c|}
\hline Field & $\begin{array}{c}\text { Typ } \\
\text { e }\end{array}$ & $\begin{array}{c}\text { Len } \\
\text { ght }\end{array}$ & $\begin{array}{c}\text { Primar } \\
\text { yKey }\end{array}$ & $\begin{array}{c}\text { Autoinc } \\
\text { rement }\end{array}$ \\
\hline $\begin{array}{l}\text { id_testi } \\
\text { moni }\end{array}$ & Int & 11 & $*$ & $*$ \\
\hline nama & $\begin{array}{c}\text { Var } \\
\text { char }\end{array}$ & 50 & & \\
\hline $\begin{array}{l}\text { pekerja } \\
\text { an }\end{array}$ & $\begin{array}{c}\text { Var } \\
\text { char }\end{array}$ & 50 & & \\
\hline
\end{tabular}




\begin{tabular}{|l|c|c|l|l|}
\hline $\begin{array}{l}\text { komen } \\
\text { tar }\end{array}$ & Text & & & \\
\hline Foto & $\begin{array}{c}\text { Var } \\
\text { char }\end{array}$ & 100 & & \\
\hline
\end{tabular}

\section{Diagram Konteks}

Diagram Konteks merupakan diagram rancangan sistem yang digunakan untuk menggambar struktur kerja sistem pada Sistem Infromasi Akademik Berbasis Web pada Politeknik Sains dan Teknologi Wiratama Maluku Utara, Berikut merupakan tampilan diagram konteks ditampilakan pada gambar sebagai berikut:

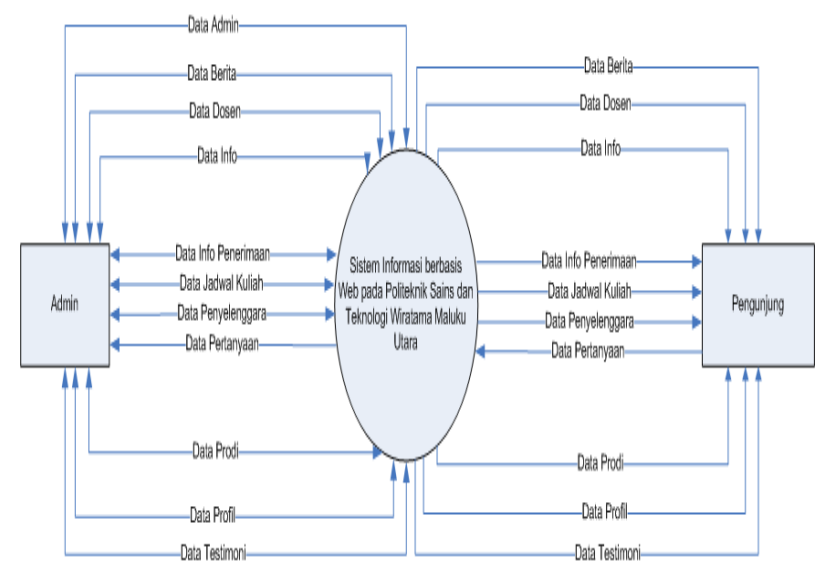

Gambar 4 : Diagram Konteks

\section{DFD Level 1}

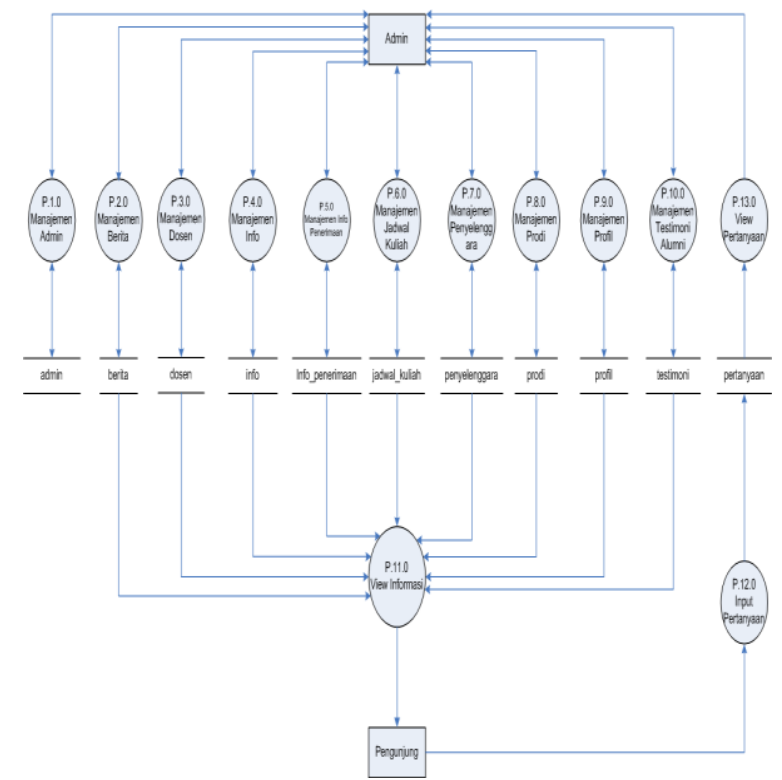

Gambar 5 : DFD Level 1
ERD (Entity Relationship Diagram)

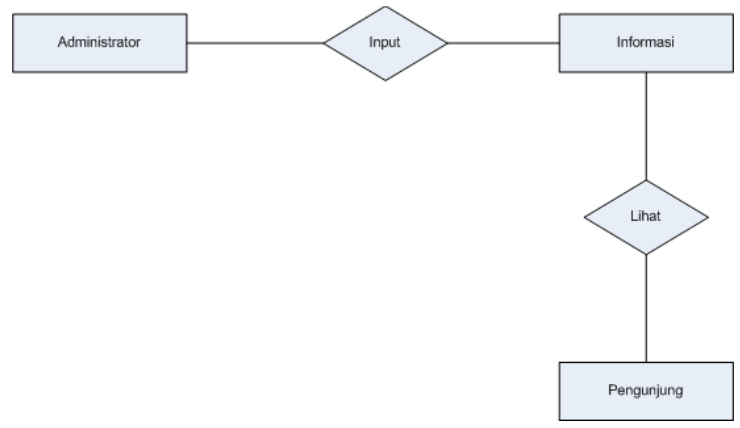

Gambar 6 : ERD

\section{Relasi Tabel}

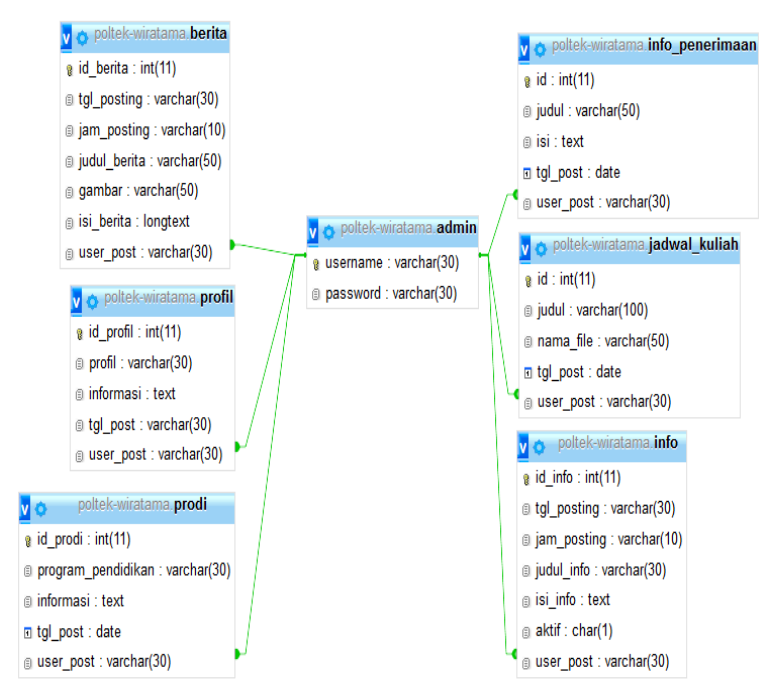

Gambar 7 : Relasi Tabel

Perancangan Antarmuka Pengguna (User Interface)

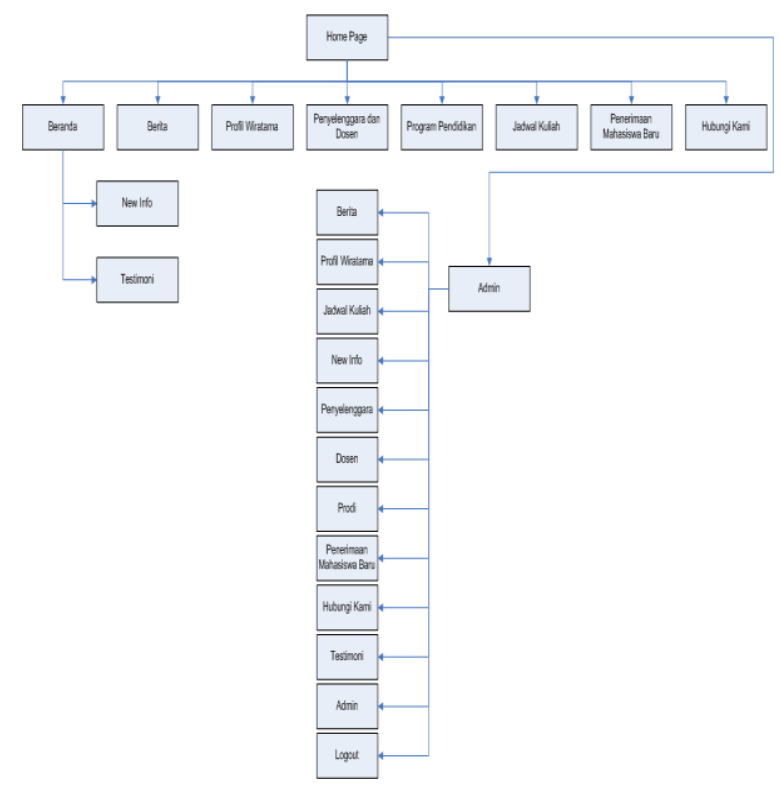


Gambar 8 : Antarmuka pengguna

\section{IMPLEMENTASI SISTEM}

\section{Halaman Form Login Admin}

Halaman Login Admin merupakan tampilan login sistem dimana admin dapat mengelola informasi pada sistem tersebut dengan memasukan user name dan password pada sistem tersebut, berikut merupakan tampilan login admin di tampilakn pada gambar sebgai berikut:

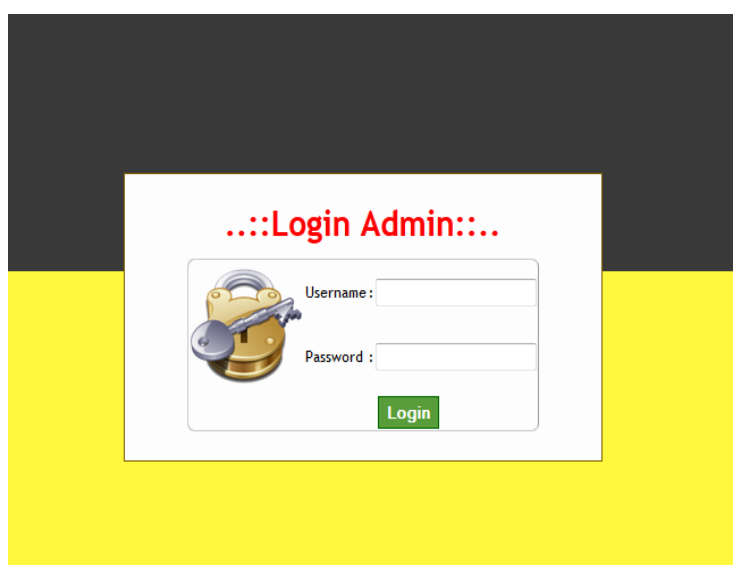

Gambar 9: Halaman Form Login

\section{Halaman Beranda (Home Page)}

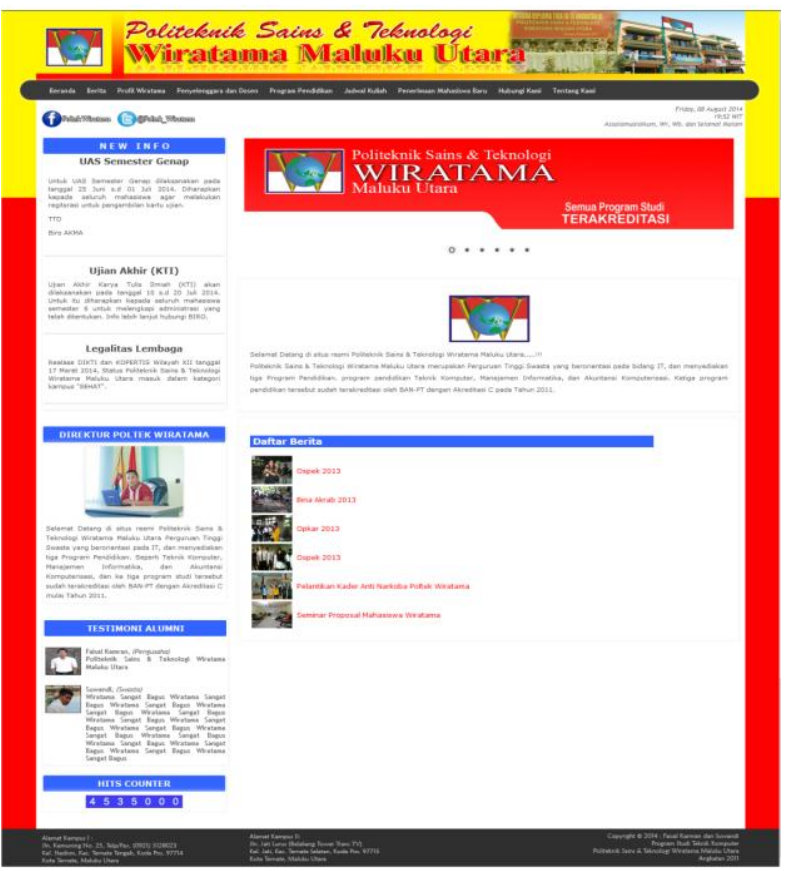

Gambar 10 : Tampilan Beranda

\section{KESIMPULAN}

Dari hasil Perancangan dan Implementasi Sistem Informasi Akademik Berbasis Web Pada Politeknik Sains dan Teknologi Wiratama Maluku Utara, menggunakan bahasa pemrograman PHP, HTML, CSS dan database MySql. Diharapkan dapat memberikan kemudahan pada pihak kampus dalam menyelenggarakan informasi serta kegiatan kampus dan menunjang kinerja administrasi dalam mengelola informasi tersebut agar masyarakat atau mahasiwa yang ingin mengetahui informasi dan kegiatan kampus dapat melihat pada sistem tersebut

Berdasarkan kesimpulan di atas, maka diajukan saran sebagai berikut.: Sistem ini dapat diterapkan sebagai media pemberian informasi yang mudah, luas dan terjangkau baik kepada Mahasiswa dan Masyarakat, Untuk Penilitian berikut agar sistem tersebut dapat di kembangkan dan di sempurnakan terutama pada desain menu tampilan agar lebih menarik

\section{DAFTAR PUSTAKA}

Kadir Abdul. 2003. Pengenalan Sistem Informasi. ANDI, Yogyakarta

Moekijat. 2005. Pengantar Sistem Informasi Manajemen. Mandar Maju, Badung

Kadir Abdul 2008. Tuntunan Praktis: Belajar Database Menggunakan MySQL. ANDI,Yogyakarta

Pratama Widhi dan Nugraha Antonius. 2010. Cara Mudah Membangun Aplikasi PHP. Media Kita, Jakarta Jayan. 2010. CSS Untuk Orang Awam (membangun website tanpa tabel, fleksibel dan \& efektif). Maxikom, Palembang. 
Dermawan Deni dan Hendra Deden P. 2013. Desain dan Pemrograman Website. PT. Remaja Rosdakarya, Bandung

Saputra Agus. 2011. Trik dan Solusi Jitu Pemrograman PHP. PT. Elex Media Komputindo, Jakarta

Rizka Liatmaja, Indah Uly Wardati, Sistem Informasi Akademik Berbasis Web Pada Lembaga Bimbingan Belajar Be Excellent Pacitan, Indonesian Jurnal on Networking and Security (IJNS), Volume 2 No 2 - April 2013 - ISSN: 2302-5700

Gurid Budi Wiyono, Indah Uly Wardati, Pembangunan Sistem Informasi Akademik Pada Sekolah Menengah Pertama (SMP) Negeri III Tegalombo, IJNS - Indonesian Journal on Networking and Security - Volume 3 No 3 - Juli 2014, ISSN: 2302-5700 (Print) 2354-6654 (Online)

Muhdar Abdurahman, Sistem Informasi Jadwal Perkuliahan Berbasis Web Mobile Pada Politeknik Sains Dan Teknologi Wiratama Maluku Utara, Indonesian Journal on Networking and Security - Volume 5 No 2 - Mei 2016, ISSN : 2302-5700 (Print) 2354-6654 (Online) 